\title{
POLICY FOR PROMOTING ANALYTIC RIGOR IN INTELLIGENCE: PROFESSIONALS' VIEWS AND THEIR PSYCHOLOGICAL CORRELATES
}

\author{
David R. Mandel*, Tonya L. Hendriks*, \& Daniel Irwin** \\ *Defence Research and Development Canada \\ **Department of National Defence \\ Correspondence to first author at $\underline{\text { drmandel66@gmail.com }}$
}

\begin{abstract}
Following significant intelligence failures, the United States intelligence community adopted Intelligence Community Directive 203 (ICD203) to promote analytic rigor. This study developed two reliable psychometric scales to examine how strongly intelligence professionals $(N=108)$ endorsed the ICD203 facets and the extent to which they believed their organizations complied with those facets. All facets yielded a high level of endorsement and perceived organizational compliance and the endorsement scale revealed three principal components ("unbiased", "rigorous", and "relevant"). Facets reflecting intelligence aims (e.g., "be unbiased") were endorsed more strongly than those reflecting means (e.g., "use visualizations"). As well, organizations' compliance was judged to fall short of the level of support personally endorsed. ICD203 endorsement was positively related to conscientious and actively open-minded thinking, whereas perceived ICD203 compliance was positively correlated with conscientiousness, job satisfaction and affective and normative commitment. The new scales could be profitably applied in future research on intelligence policy-related issues.
\end{abstract}

Keywords: intelligence analysis, public policy, organizational compliance, psychological correlates 
For many large bureaucracies, the pursuit of quality assurance and customer confidence represents an enduring challenge (Travers, 2007). The success or failure of these efforts often depends on employee buy-in (Kirchner et al., 2012; Weiner, 2009). If employees perceive incongruence between such efforts and their personal values, or if they view their organization as noncompliant with its stated values, organizational cynicism may ensue and undermine job satisfaction, organizational commitment, and performance (Abraham, 2000; Chiaburu et al., 2013; Dean et al., 1998).

The domain of national security intelligence presents a unique and under-explored organizational context in which to examine professional attitudes towards quality assurance policies. Tasked with providing timely decision support to policymakers, the intelligence community (IC) has long grappled with the aim of ensuring both process and product qualitynamely, analytic rigor (Zelik et al., 2007a). In the US, the IC's commitment to analytic rigor gained unprecedented political salience in the wake of two catastrophic intelligence failures: the terrorist attacks of September 11, 2001 and the 2002 Iraqi weapons of mass destruction misestimate that served as a pretext for the 2003 US invasion of Iraq (Marchio, 2014; Zelik et al., 2007b). Following lengthy post-mortems, US policymakers attributed these failures to weak tradecraft and mandated the introduction of a formal analytic policy (Pigg, 2009). ${ }^{1}$

On December 17, 2004, the US Congress passed the Intelligence Reform and Terrorism Prevention Act, establishing the Office of the Director of National Intelligence (ODNI). In 2007, ODNI released Intelligence Community Directive 203 (ICD203) which was updated in 2015 (ODNI, 2007, 2015). ICD203 comprises the following five IC analytic standards:

1. Objectivity;

2. Independence of political consideration;

3. Timeliness;

4. Utilization of all available sources of intelligence information; and

5. Analysis that implements and exhibits analytic tradecraft standards.

ICD203 further expands the last standard on analytic tradecraft into these nine facets:

1. Properly describing quality and reliability of underlying sources, data, and

${ }^{1}$ The UK undertook similar efforts to standardize and professionalize intelligence production based on findings of the 2004 Review of Intelligence on Weapons of Mass Destruction (Goodman \& Omand, 2008). 
methodologies;

2. Properly expressing and explaining uncertainties or confidence in major analytic judgments;

3. Properly distinguishing between underlying intelligence information and analysts' assumptions and judgments;

4. Incorporating analysis of alternatives;

5. Demonstrating customer relevance and addressing implications;

6. Using clear and logical argumentation;

7. Explaining change to or consistency of analytic judgments;

8. Making accurate judgments and assessments; and

9. Incorporating effective visual information where appropriate.

While many of these standards are evident in intelligence products dating back to the 1940s (Marchio, 2014), ICD203 represents an unprecedented effort to coordinate best practices across the US IC. The policy has drawn mixed commentary. Proponents have hailed it as "one of the most significant accomplishments in IC reform," claiming that it injects rigor into products and processes while holding practitioners accountable (Cardillo, 2010, p. 2). Meanwhile, critics have warned that ICD203 neglects the root causes of weak tradecraft and simply provides bureaucratic cover for novice analysts (Gentry, 2015). A recent report by Barry Zulauf, ODNI's IC Analytic Ombudsman, to the US Senate Select Committee on Intelligence outlines multiple violations of ICD203 linked to politicization of intelligence amidst what Zulauf describes as the US being "in a hyperpartisan state, unlike any in recent memory" (ODNI, 2021, p. 1).

Despite the longevity of debate about analytic standards and the high stakes involved, there has been remarkably little empirical research examining any policy dimension of ICD203. Marcoci et al. (2019) found that individual assessors do not reliably rate analytic product quality using the ICD203 rubric, unless ratings of three or more assessors are averaged. However, we are unaware of any studies measuring intelligence professionals' attitudes towards ICD203. Nor have psychological correlates of these attitudes been examined. These are important considerations, given the aforementioned consequences of misalignment between employees' values and organizational policies. Moreover, by identifying the correlates of commitment to analytic rigor (measured by support for ICD203), intelligence organizations could tailor their 
recruitment processes to select for applicants who score highly on these measures, in line with the recommendations of studies aimed at improving expert judgment (Karvetski et al., 2013; Mellers, Stone, Murray et al., 2015).

\section{The Present Research}

In this research, we examined the extent to which Canadian intelligence professionals endorsed the directives for promoting analytic rigor captured in ICD203. Although Canada has a strong intelligence-sharing relationship with the US and some of its intelligence professionals are aware of ICD203, Canada's IC is not mandated to follow this policy. Moreover, Canada has no nationally equivalent policy. Thus, it is instructive to examine how intelligence professionals view the facets of ICD203 in cases where there is no institutional or community-wide pressure to agree with the policy. To explore professionals' views of the ICD203 analytic policies, we constructed two novel psychometric scales that tapped the specific 13 facets of ICD203. The ICD203 Professional Attitudes Scale (ICD203-PAS) was designed to elicit attitudinal support for the items, whereas the ICD203 Organizational Compliance Scale (ICD203-OCS) was designed to elicit judgments of how well respondents' current organizations complied with the same 13 ICD203 facets. These scales permitted an investigation of support for and perceived organizational compliance with the ICD203 facets of analytic rigor, thus allowing the following questions to be addressed: (1) Which ICD203 facets have the greatest endorsement by intelligence professionals? (2) Which facets are perceived as being best followed by professionals' organizations? (3) Which facets represent the largest gaps between professional endorsement and perceived organizational compliance? We also conducted a principal components analysis (PCA) of the attitudinal scale items in order to explore the main components of analytic rigor captured in ICD203.

A second research aim was to examine several psychological correlates of the two new scales. One psychological measure we examined was conscientiousness, which refers to being dependable, hardworking, persevering, and achievement-oriented (Digman, 1990).

Conscientiousness, one of five personality dimensions comprising the Big Five Inventory (BFI; John \& Srivastava, 1999), is a strong predictor of job performance across all occupational groups (Barrick \& Mount 1991; Barrick et al., 2001; Hogan \& Ones, 1997). Conscientious individuals tend to be organized and efficient (Barrick et al., 1993; Barry \& Stewart, 1997; McCrae \& John, 1992), and adhere closely to organizational norms and rules (DeYoung et al., 2002; Marcus \& 
Schuler, 2004; Slaughter et al., 2020). By contrast, individuals scoring low on conscientiousness tend to be less success-driven and more likely to engage in antisocial, norm-violating behaviors (Friehe \& Schildberg-Hörisch, 2017; Ozer \& Benet-Martínez, 2006). Research has linked conscientiousness to compliance with a variety of organizational policies and best practices, ranging from information security standards (McCormac et al., 2017) to public health regulations aimed at slowing the spread of the COVID-19 (Brouard et al., 2020). Accordingly, we hypothesized that conscientiousness will be positively correlated with support for ICD203 (i.e., with ICD203-PAS).

Another psychological measure of interest was actively open-minded thinking (AOT). AOT reflects an individual's openness to alternative opinions, sensitivity to contradictory evidence, and willingness to delay closure (Baron, 1985, 1993; Baron et al., 2015; Stanovich \& Toplak, 2019). AOT is associated with reduced cognitive biases across several tasks (Baron, 2008; Gurcay-Morris, 2016; Smith \& Levin, 1996; Stanovich \& Toplak, 2019; Toplak et al., 2017; West et al., 2008). Of particular relevance to the IC, AOT has been shown to improve the accuracy of probabilistic judgments made under conditions of uncertainty (Haran et al., 2013; Juvina et al., 2020; Mellers, Stone, Murray et al., 2015; Mellers, Stone, Atanasov et al., 2015; Telock \& Gardner, 2015). In the context of large-scale geopolitical forecasting tournaments, open-minded forecasters tend to engage in additional information acquisition and update their forecasts regularly, boosting accuracy (Juvina et al., 2020; Mellers, Stone, Murray et al., 2015; Tetlock \& Gardner, 2015). Given the similarity between the questionnaire items used to measure AOT (Baron, 1985, 1993; Baron et al., 2015) and the edicts of ICD203, we hypothesized that AOT will be positively correlated with ICD203-PAS.

We also tested hypotheses regarding psychological correlates of professionals' views of their organization's compliance with ICD203 (ICD203-OCS). Employees who perceive a lack of fit between their personal characteristics and those of their organization may exhibit lower levels of commitment (Ostroff et al., 2005). Similarly, quality assurance efforts seen as performative rather than substantive may engender organizational cynicism, or negative attitudes towards the organization based, in part, on the belief that it lacks integrity (Abraham 2000; Dean et al., 1998). Cynical employees, in turn, may exhibit lower levels of organizational commitment (Chiaburu et al., 2013; Kristof, 1996). Organizational commitment is defined as "a psychological link between the employee and his or her organization that makes it less likely that the employee 
will voluntarily leave the organization," (Allen \& Meyer, 1996, p. 252). Allen and Meyer (1990, 1996) distinguish among three components of organizational commitment. Affective commitment captures emotional attachment to, identification with, and involvement in the organization (i.e., employees stay because they want to). Continuance commitment reflects the perceived costs of leaving the organization (i.e., employees stay because they need to). Finally, normative commitment refers to feelings of obligation to remain in the organization (i.e., employees stay because they ought to). These three components have been measured in a variety of organizational contexts and are important predictors of job performance, particularly when factored together (Jaramillo et al., 2005; Meyer et al., 2002).

We hypothesized that employees who viewed their organization as committed to analytic rigor (as indicated by high levels of ICD203-OCS) would feel a stronger sense of attachment to their organization (affective commitment) and would believe that it deserved their continued service (normative commitment). Amos and Weathington (2008) found that individuals who viewed their organization as committed to superior quality and service exhibited higher levels of both normative and affective commitment. More broadly, perceived value congruence between employees and their host organization is positively linked to both normative and affective commitment (Amos \& Weathington, 2008; Verquer et al., 2003). Thus, we further tested whether incongruence between individual support for the ICD203 facets and perceived organizational compliance, as measured by the difference between personal support and perceived organizational compliance, would correspond negatively with both forms of commitment, even after controlling for ICD-OCS scores. Given that continuance commitment reflects the anticipated costs of leaving an organization (e.g., reduced income), we did not expect to observe a relationship with perceived organizational compliance with ICD203, nor with individualorganizational incongruence. In previous research, neither value congruence, nor organizational support for specific values was significantly related to continuance commitment (Amos \& Weathington, 2008).

Finally, we assessed job satisfaction, broadly defined as "a pleasurable or positive emotional state resulting from the appraisal of one's job or job experiences," (Locke, 1976, p. 1304). It is considered an important determinant of performance in virtually all occupations (Sheley \& Nock, 1979). Studies have shown that employees' perception of an organizational service orientation (i.e., an organizational affinity for service excellence and adherence to quality 
assurance procedures) is positively related to job satisfaction in a variety of sectors (e.g., Hong et al., 2013; Eren et al., 2013; Yoon et al., 2007). Moreover, employees who perceive goal/value congruence with their host organization tend to report higher levels of job satisfaction (Boxx et al., 1991; Verquer et al., 2003). Accordingly, we hypothesized that ICD203-OCS will be positively correlated with job satisfaction and that, controlling for ICD-OCS scores, incongruence between ICD203-PAS and ICD203-OCS will be negatively correlated with job satisfaction.

\section{Method}

\section{Participants}

Prior to initiation, this experiment was reviewed and approved by the Defence Research and Development Canada Human Research Ethics Committee. Participants were recruited by email with the assistance of their managers and trainers. ${ }^{2} \mathrm{~A}$ total of 108 participants $(72.2 \%$ males) completed the entire study. Participants were professionals working in the Canadian IC (e.g., those attending relevant training courses, analysts, managers, etc.) who were proficient in English. The mean age was $38.4(S D=9.40)$ and the mean number of years working in the intelligence community was $8.92(S D=7.89)$. The sample consisted of $50.0 \%$ civilian and $50.0 \%$ Canadian Armed Forces (one participant did not respond). Among the military participants, the largest rank subgrouping was 'Junior Non-Commissioned Member' (NCM; $22.2 \%$ ), followed by 'Junior Officer' (13.9\%), 'Senior Officer' (9.3\%), and 'Senior NCM' (4.6\%). The highest education level groupings were 'university graduate degree' $(44.0 \%)$ and 'university undergraduate degree' (37.6\%), indicating that the sample was quite educated. With respect to their primary role in the organization, $65.1 \%$ of the participants indicated that they were intelligence analysts, followed by manager of analysts (16.5\%), other (15.6\%), and analytic trainer/methodologist (2.8\%). Among the analysts, $91.5 \%$ worked in an all-source environment and 5.6\% worked in a single-source environment. In terms of level of intelligence supported, $76.1 \%$ of the analysts indicated that they currently worked in a strategic environment, $12.7 \%$ worked in an operational environment, and $11.3 \%$ worked in a tactical environment. Fifteen participants (13.9\%) reported having heard of ICD203 prior to the study.

\footnotetext{
${ }^{2}$ The role of the managers and trainers was to communicate the information about the study to their staff; they did not have any direct involvement with scheduling participants or running participants, they were unaware of the names of the participants who did or did not participate, and they did not have access to the data.
} 


\section{Measures $^{3}$}

ICD203 scales. Two 13-item scales, derived directly from the 13 ICD203 facets (ODNI, 2015), were developed to assess (a) attitudinal support for the facets of the ICD203 analytic policy (ICD203-PAS) and (b) beliefs about organizational compliance with the same set of facets covered in the policy (ICD203-OCS). For both scales, participants rated the extent to which they agreed with each of the statements on a 7-point Likert scale ranging from 1-7 (strongly disagree to strongly agree). The wording of the latter part of each of the items was identical across the two scales. In ICD203-PAS, the first part of the item was worded to reflect the professional's attitudinal support for the ICD203 facets. The specific items of ICD203-PAS are as follows and always began with the sentence stem "It is important to me that I...":

1. perform my analytic and informational functions from an unbiased, objective perspective.

2. provide assessments that are not distorted by or altered with the intent of supporting a particular policy or political viewpoint.

3. deliver analytic products in a timely manner, allowing them to be actionable by consumers.

4. am informed by all relevant information that is available to the analytic element in my analyses.

5. properly describe the quality and credibility of underlying sources in my analytic products.

6. properly caveat and express uncertainties or confidence in analytic judgments in my analytic products.

7. properly distinguish between underlying intelligence and my (or others') assumptions and judgments in my analytic products.

8. incorporate alternative analysis where appropriate (e.g., explaining the strengths and weaknesses of alternative hypotheses in light of both available information and information gaps) in my analytic products.

9. demonstrate relevance to Canadian national security in my analytic products.

10. present analytic products in ways that facilitate clear understanding of the information

\footnotetext{
${ }^{3}$ Materials and data for this study are available at $\mathrm{https://osf.io/9bym2/.}$
} 
and reasoning underlying my analytic judgments.

11. deliver a key message that is either consistent with previous production on the topic or, if the key analytic message has changed, the product will highlight the change and explain its rationale and implications in my analytic products.

12. make the most accurate judgments possible given the information available.

13. deliver analytic products that effectively incorporate visual information where appropriate.

In ICD203-OCS, the first part of the item was worded to reflect the participant's view of their organization's commitment to the policy (i.e., "In my organization,..."). However, the content of the 13 items was otherwise matched to ICD203-PAS. For instance, in comparison with the first item of the ICD203-PAS, the comparable item in ICD203-OCS was "In my organization, analysts and managers perform their analytic and informational functions from an unbiased, objective perspective."

Conscientiousness. Our measure of conscientiousness was taken from the 44-item self-report BFI designed to measure the following five dimensions of personality: Openness, Conscientiousness, Agreeableness, Extraversion, and Neuroticism (John \& Srivastava, 1999). Items are written in both directions and reversal items are reverse scored. All BFI subscales are highly reliable including across cultures and languages (McCrae et al., 1998; Ortiz et al., 2007). In this study, we collected data on the nine items of the Conscientiousness Subscale only. The Conscientiousness Subscale measures a tendency to be orderly, responsible, and dependable (e.g., "I see myself as someone who does a thorough job"). Responses to this item were made on a 5-point Likert scale ranging from 1 (strongly disagree) to 5 (strongly agree).

Actively open-minded thinking. The 8-item AOT scale (Baron et al., 2015) assesses a style of reasoning that includes the tendency to revise one's beliefs in response to new information and to take into consideration evidence that goes against their beliefs (e.g., "People should revise their beliefs in response to new information or evidence"). Responses to these items were made on a 5-point Likert scale ranging from 1 (strongly disagree) to 5 (strongly agree).

Organizational commitment. Organizational commitment was measured using Allen and Meyer's (1990) Affective Commitment Scale (ACS), Continuance Commitment Scale (CCS), and Normative Commitment Scale (NCS). The three components of organizational commitment 
are defined as follows:

A. Affective refers to employees' emotional attachment to, identification with, and involvement in, the organization (e.g., "I would be very happy to spend the rest of my career with this organization");

B. Continuance refers to commitment based on the costs that employees associate with leaving the organization (e.g., "It would be very hard for me to leave my organization right now, even if I wanted to"); and

C. Normative refers to employees' feelings of obligation to remain with the organization (e.g., "I think that people these days move from company to company too often" [Allen \& Meyer, 1990, pp. 6-7]).

The affective, continuance, and normative subscales each consist of eight items. These items were rated on a 7-point Likert scale ranging from 1 (strongly disagree) to 7 (strongly agree).

Job satisfaction. The following item taken from the 2015 US Federal Employee Survey (see Office of Personnel Management, 2015) was used to measure job satisfaction: "Considering everything, how satisfied are you with your job?" Responses to this item were made on a 5-point Likert scale ranging from 1 (very dissatisfied) to 5 (very satisfied).

\section{Procedure}

The data were collected online anonymously using the Qualtrics survey platform (http://www.qualtrics.com) during a session that lasted approximately 15 minutes. After providing consent, participants completed their ratings of ICD203-PAS and ICD203-OCS. Order of these scales was counterbalanced. Next, participants completed the AOT scale and Conscientiousness subscale, which were presented in random order. Participants then completed the Organizational Commitment Scale and rated their job satisfaction. Within each of the aforementioned scales, item order was fixed. Lastly, participants provided demographic information and indicated whether they had been familiar with ICD203 prior to the study (yes or no).

\section{Results}

\section{Scale characteristics}

Aside from job satisfaction, which was measured using a single item, we standardized all 
scale items prior to analysis, which had the effect of slightly improving scale reliabilities. The reliabilities were as follows: for ICD203-PAS, Cronbach's alpha $(\alpha)=.87$; for ICD203-OCS, $\alpha=$ .89; for AOT, $\alpha=.69$; for conscientiousness, $\alpha=.80$; for ACS, $\alpha=.73$; for CCS, $\alpha=.79$; and for NCS, $\alpha=.75$. All scales therefore showed acceptable reliability. We further conducted a PCA on ICD203-PAS responses. The analysis, which used Varimax rotation with Kaiser normalization, converged in six iterations. As Table 1 shows, a three-component solution with eigenvalues of $5.10,1.64$, and 1.03 , accounting for $39.26 \%, 12.64 \%$, and $7.90 \%$ of the variance in ICD203PAS, respectively, was obtained. The components accounted for $59.80 \%$ of response variance.

Per Table 1, the four items that principally loaded onto the first component refer to the ability to remain unbiased (unbiased, objective; not distorted/altered to support a view; makes the most accurate judgments possible; express uncertainties or confidence in judgments). The five items that principally loaded onto the second component represent items that refer to the methodological rigor of the analysis (describe source quality and credibility; incorporate alternative analysis where appropriate; incorporates visual information where appropriate; distinguish intelligence vs. analysts' assumptions; present in ways to facilitate clear understanding). Finally, the four items that principally loaded onto the third component refer to relevance of the analysis for the customer (demonstrate relevance to Canadian national security; deliver a key message that is consistent with previous or highlights changes; delivered in a timely manner; informed by all relevant information). Accordingly, we assigned the labels Unbiased, Rigorous, and Relevant, to Components 1-3, respectively.

\section{Responses to ICD203 scales $^{4}$}

Table 2 shows mean values of ICD203-PAS, ICD203-OCS, and the difference between these scales. The mean level of attitudinal support for the ICD203 facets was strong across the entire set. Using a Newman-Keuls test, mean scores for the four items with the highest means (accurate, timely, objective, not distorted to support political view) were significantly greater than mean scores for the four items with the lowest means (uses alternate analysis, incorporates visual information, describes quality and credibility, has relevance to Canadian national security). The mean score for Item 8 (uses alternate analysis) was significantly lower than that of all of the other items except Item 13 (incorporates visual information). Other item means did not

\footnotetext{
${ }^{4}$ Analyses in this section use the unstandardized versions of ICD203-PAS and ICD203-OCS so that the item means can be meaningfully interpreted.
} 
differ significantly from one another.

Table 2 also shows that, on average, professionals agreed to some extent that all facets of ICD203 were addressed by their organization. A Newman-Keuls test revealed that the mean score for Item 8 (uses alternate analysis) was significantly lower than that of all of the other items. Similarly, the mean score for Item 5 (describes source quality and credibility) was also significantly lower than that found for each of the 11 items that had higher mean scores. The mean score for Item 2 (not distorted/altered to support a view) was significantly higher than that found for each of the six items with the lowest mean scores, while the mean score for Item 12 (makes accurate judgments) was significantly higher than that found for the four items with the lowest mean scores. Other item means did not differ significantly from one another.

To explore the extent to which there are perceived differences between analysts' attitudes towards the ICD203 policy and their views of their organization's compliance with the policy, we calculated difference scores by subtracting ICD203-OCS scores from ICD203-PAS scores. All difference scores except for Item 13 (incorporates visual information; $t[107]=1.27, p=.21$ ) were significantly greater than 0 , indicating that professionals endorsed the policy more strongly than they perceived their organizations as complying with it. Furthermore, results of the Newman-Keuls test revealed that the mean difference score for Item 13 (incorporates visual information) was significantly lower than the mean difference score obtained for each of the other items. In addition, the three items with the largest disparity in mean scores had significantly greater difference scores than the four items with the smallest disparity in mean score. The mean difference score for Item 8 (uses alternative analysis), the item with the largest disparity, was also significantly greater than the mean difference score for Item 12 (makes accurate judgments). None of the other item means differed significantly.

\section{Correlates of ICD203 scales}

Figure 1 shows the correlations among the ICD203 scales, including the three ICD203PAS component scores, and the other measures taken in this study. As hypothesized, ICD203PAS was significantly correlated with both conscientiousness and AOT. Conscientiousness was significantly correlated with each of the three ICD203-PAS components and AOT was significantly correlated with the Unbiased and Rigorous components. As conscientiousness and AOT were positively correlated, we conducted a linear regression analysis predicting ICD203PAS scores from conscientiousness and AOT scores to determine whether each predictor had a 
significant effect. Both conscientiousness $(\beta=.51, t=6.89, p<.001)$ and AOT $(\beta=.40, t=4.87$, $p<.001)$ significantly predicted ICD203-PAS, and the model was significant, $F(2,102)=46.90$, $R^{2}=.48, p<.001$. Further examining these relations, we conducted three additional regression analyses predicting each of the three components from conscientiousness and AOT. Consistent with our bivariate analyses, the AOT scale significantly predicted Unbiased $(\beta=.66, t=4.27, p$ $<.001)$ and Rigorous $(\beta=.35, t=2.11, p=.037)$, but not Relevant $(\beta=.03, t=0.35, p=.728)$. Meanwhile, conscientiousness predicted Unbiased ( $\beta=.47, t=3.38, p=.001)$, Rigorous ( $\beta$ $=.52, t=3.48, p=.001)$, and Relevant $(\beta=.45, t=2.95, p=.004)$. The model for Unbiased was significant $\left(F[2,102]=19.63, R^{2}=.28, p<.001\right)$, as were the models for Rigorous $(F[2,102]=$ $\left.10.77, R^{2}=.17, p<.001\right)$ and Relevant $\left(F[1,103]=8.71, R^{2}=.08, p=.004\right)$.

Next, we examined the relation between ICD203-OCS and the individual difference measures taken in this study. Supporting our hypotheses, ICD203-OCS scores were positively correlated with job satisfaction, affective commitment, and normative commitment, but did not correlate significantly with continuance commitment. ICD203-OCS scores were also positively correlated with conscientiousness. To further explore these findings, we conducted a regression analysis predicting ICD203-OCS scores from job satisfaction, affective commitment, normative commitment, and conscientiousness. While conscientiousness $(\beta=.36, t=3.59, p=.001)$ significantly predicted ICD203-OCS, the other predictors did not independently significantly predict ICD203-OCS. The overall model was significant, $F(4,95)=9.757, R^{2}=.29, p<.001$.

Finally, as expected, we found that the difference between ICD203-PAS and ICD203OCS was negatively correlated with job satisfaction $(r=-.27, p=.006)$, affective commitment ( $r$ $=-.18, p=.073)$, and normative commitment $(r=-.24, p=.014)$, and there was no significant correlation with continuance commitment $(r=.05, p=.640)$. After controlling for ICD203-OCS, the partial correlations between the difference measure and satisfaction, affective commitment, and normative commitment were all non-significant (all $p \geq .20$ ). Therefore, correlations observed with the difference measure do not explain variance above and beyond what the primary ICD203-OCS reveals.

\section{Discussion}

Intelligence organizations have long sought to promote analytic rigor. The US IC formalized such efforts and issued policy directives in the form of ICD203, outlining what facets of rigor are viewed by ODNI as most important. In this research, we asked two basic questions: 
First, to what extent do intelligence professionals endorse the contents of ICD203 as valid professional tenets worth aspiring to? Second, to what extent do they view their organizations as compliant with such tenets? The study revealed several important findings. First, we verified that the scales developed to address these questions have sound psychometric properties. Both scales displayed good reliability, which bodes well for future use by researchers and intelligence organizations seeking to self-monitor. Moreover, the principal components analysis of ICD203PAS yielded a solution that not only explained a substantial proportion of response variability, but which revealed a coherent structure in which about one third of the items focus on being unbiased in one's thinking and judgments, another third of the items focus on being rigorous in one's thinking and judgments, and the remaining third focuses on striving for relevance to intelligence customers. These higher-order concepts help to frame what ICD203 is "about" and could be used by ODNI to socialize the policy in intelligence training. This could contribute to implementing the recent recommendation of the ODNI IC Analytic Ombudsman that would "require an analytic standards and objectivity course prerequisite as part of completing the IC Advanced Analyst Program (ICAAP)" (ODNI, 2021, p. 11).

Our findings also revealed a very high degree of support, in general, for the ICD203 facets, and although participants tended to view their organizations as complying well with the ICD203 facets, they judged compliance as falling short of the level of support that they personally expressed. At face value, these findings suggest that professionals are more willing to follow ICD203 policy than their organizations manage to achieve. However, the differences may also represent a case of self-enhancement, as it is common for individuals to regard themselves as better than average on a range of self-relevant measures (Alicke \& Govorun, 2005; Taylor, 1991). In future research, it might be of value to include an independent measure of selfenhancement, which could be used as a statistical control. Another approach that could be taken in future research would be to adapt the ICD203 scales so that participants rank the facets in terms of importance or organizational compliance, thus ensuring that all participants spread their assessments from low to high over the set of scale items.

Third, although participants tended to support all of the ICD203 facets, the differences in support were informative. All of the most highly endorsed ICD203-PAS items refer to aims of intelligence such as being accurate, timely, and unbiased. In contrast, the items that received the weakest endorsement refer to means of improving intelligence analysis, such as using alternative 
analysis, incorporating visual information into analysis, and describing source quality and information credibility. Evidently, intelligence professionals agree more strongly with the aims and objectives that motivate policy for promoting analytic rigor than they do with the specific means proposed for achieving such objectives. These findings align with research showing that employees may endorse organizational goals while exhibiting skepticism towards the policies chosen to achieve them (Stanley et al., 2005).

Our results also resonate with critiques of intelligence tradecraft methods that emphasize the scientifically undocumented nature of their effectiveness and their conceptual shortcomings (e.g., Chang et al., 2018; Dhami et al., 2015; Mandel \& Tetlock, 2018), as well as with findings that intelligence analysts often do not use recommended methods such as structured analytic techniques because they remain unconvinced of their effectiveness (Coulthart, 2016). Recent studies suggest that this skepticism is not unwarranted. For instance, one of the most vaunted structured techniques in the IC — Analysis of Competing Hypotheses (Heuer, 1999)— has either not improved or else deteriorated judgment quality in several recent experiments (Mandel et al., 2018; Karvetski \& Mandel, 2020; Karvetski et al., 2020; Whitesmith, 2019). Future research might examine whether ICD203 facets that reflect aims of intelligence analysis are also rated more positively than facets that reflect means in other intelligence communities, including the US IC where ICD203 is in force.

Our findings also offered support for hypotheses regarding the correlates of the two ICD203 scales. As predicted, support for the facets of ICD203 was positively correlated with conscientiousness and AOT. Although our study cannot establish causation, we believe it is more plausible that greater support for the ICD203 facets is attributable to dispositions such as conscientiousness and an actively open-minded thinking style than the other way around. Indeed, the pattern of correlations between these dispositions and the component scores strengthens our conviction since the first two components (Unbiased and Rigorous), which specifically pertain to facets of thinking style, are significantly correlated with AOT, whereas the third component (Relevant), which does not pertain to thinking style, did not correlate with AOT. By comparison, we might expect conscientious individuals to score higher on each of the three components, each of which reflects an expression of diligence. In fact, this is what was observed. Taken together, the correlations just noted have implications for how intelligence organizations could screen and select analysts. Whereas prior research indicates that individuals who score higher in AOT tend 
to judge more accurately (e.g., Haran et al., 2013; Tetlock, 2005), our findings indicate that intelligence professionals who score high in AOT also aspire to be more accurate, unbiased, and rigorous in their thinking and judgments. Therefore, intelligence organizations might consider screening analysts for dispositions such as conscientiousness and AOT, giving more weight in selection processes to those who score highly on these measures.

As hypothesized, we also found that professionals who were more satisfied, affectively and normatively committed judged their organization to be in stronger compliance with the directives in ICD203. However, an unexpected result was that after controlling for conscientiousness, these organizational measures were not significant predictors of ICD203OCS. In hindsight, the finding is not that surprising. Conscientiousness was significantly correlated with job satisfaction and affective commitment, possibly because conscientious employees are likely to reap formal (e.g., promotion) and informal (e.g., recognition) rewards (Judge et al., 2002; Organ \& Lingl, 1995). Nevertheless, our findings demonstrate that intelligence professionals who perceive their organizations as more compliant with analytic standards are more satisfied and committed (both affectively and normatively), which may come as welcome news to ODNI and other ICs contemplating the implementation of similar public policies. 


\section{References}

Abraham, R. (2000). Organizational cynicism: Bases and consequences. Genetic, Social, and General Psychology Monographs, 126(3), 269-292.

Alicke, M. D., and Govorun, O. (2005). The better-than-average effect. In M. D. Alicke, D. A. Dunning, \& and J. I. Krueger (Eds.), The self in social judgment, studies in self and identity series (pp.85-106). New York, NY: Psychology Press.

Allen, N. J., \& Meyer, J. P. (1996). Affective, continuance, and normative commitment to the organization: An examination of construct validity. Journal of Vocational Behavior, 49(3), 252-276. doi:10.1006/jvbe.1996.0043

Allen, N. J., \& Meyer, J. P. (1990). The measurement and antecedents of affective, continuance and normative commitment to the organization. Journal of Occupational Psychology, 63(1), 1-18. doi:10.1111/j.2044-8325.1990.tb00506.x

Amos, E. A., \& Weathington, B. L. (2008). An analysis of the relation between EmployeeOrganization value congruence and employee attitudes. The Journal of Psychology, 142(6), 615-632. doi:10.3200/jrlp.142.6.615-632

Baron, J. (2008). Thinking and deciding (4th ed.). Cambridge, UK; New York, NY: Cambridge University Press.

Baron, J. (1985). What ends of intelligence components are fundamental? In S. F. Chipman \& J. W. Segal (Eds.), Thinking and learning (pp.365-390). Hillsdale, NJ: Lawrence Erlbaum.

Baron, J. (1993). Why teach thinking? An essay. Applied Psychology, 42(3), 191-214. doi:10.1111/j.1464-0597.1993.tb00731.x

Baron, J., Scott, S., Fincher, K., \& Metz, S. E. (2015). Why does the cognitive reflection test (sometimes) predict utilitarian moral judgment (and other things)? Journal of Applied Research in Memory and Cognition, 4(3), 265-284. doi:10.1016/j.jarmac.2014.09.003

Barrick, M. R., \& Mount, M. K. (1991). The Big Five personality dimensions and job performance: A meta-analysis. Personnel Psychology, 44(1), 1-26. doi:10.1111/j.17446570.1991.tb00688.x

Barrick, M. R., Mount, M. K., \& Judge, T. A. (2001). Personality and performance at the beginning of the new millennium: What do we know and where do we go next? 
International Journal of Selection and Assessment, 9(1\&2), 9-30. doi:10.1111/14682389.00160

Barrick, M. R., Mount, M. K., \& Strauss, J. P. (1993). Conscientiousness and performance of sales representatives: Test of the mediating effects of goal setting. Journal of Applied Psychology, 78(5), 715-722. doi:10.1037/0021-9010.78.5.715

Barry, B., \& Stewart, G. L. (1997). Composition, process, and performance in self-managed groups: The role of personality. Journal of Applied Psychology, 82(1), 62-78. doi:10.1037/0021-9010.82.1.62

Boxx, W. R., Odom, R. Y., \& Dunn, M. G. (1991). Organizational values and value congruency and their impact on satisfaction, commitment, and cohesion: An empirical examination within the public sector. Public Personnel Management, 20(2), 195-205. doi:10.1177/009102609102000207

Brouard, S., Vasilopoulos, P., \& Becher, M. (2020). Sociodemographic and psychological correlates of compliance with the COVID-19 public health measures in France. Canadian Journal of Political Science, 53(2), 253-258. doi:10.1017/S0008423920000335

Cardillo, R. (2010). Intelligence community reform - A cultural evolution. Studies in Intelligence, 54(3),1-7 (Extracts, September 2010).

Chang, W., Berdini, E., Mandel, D. R., \& Tetlock, P. E. (2018). Restructuring structured analytic techniques in intelligence. Intelligence and National Security, 33(3), 337-356. doi:10.1080/02684527.2017.1400230

Chiaburu, D. S., Peng, A. C., Oh, I., Banks, G. C., \& Lomeli, L. C. (2013). Antecedents and consequences of employee organizational cynicism: A meta-analysis. Journal of Vocational Behavior, 83(2), 181-197. doi:10.1016/j.jvb.2013.03.007

Coulthart, S. (2016). Why do analysts use structured analytic techniques? An in-depth study of an American intelligence agency. Intelligence and National Security, 31(7), 933-948. doi:10.1080/02684527.2016.1140327

Dean, J. W., Brandes, P., \& Dharwadkar, R. (1998). Organizational cynicism. The Academy of Management Review, 23(2), 341-352. doi:10.2307/259378

DeYoung, C. G., Peterson, J. B., \& Higgins, D. M. (2002). Higher-order factors of the Big Five 
predict conformity: Are there neuroses of health? Personality and Individual Differences, 33(4), 533-552. doi:10.1016/s0191-8869(01)00171-4

Dhami, M. K., Mandel, D. R., Mellers, B. A., \& Tetlock, P. E. (2015). Improving intelligence analysis with decision science. Perspectives on Psychological Science, 10(6), 753-757. doi:10.1177/1745691615598511

Digman, J. M. (1990). Personality structure: Emergence of the five-factor model. Annual Review of Psychology, 41(1), 417-440. doi:10.1146/annurev.ps.41.020190.002221

Eren, S. S., Eren, M. Ş., Ayas, N., \& Hacioglu, G. (2013). The effect of service orientation on financial performance: The mediating role of job satisfaction and customer satisfaction. Procedia, Social and Behavioral Sciences, 99, 665-672. doi:10.1016/j.sbspro.2013.10.537

Friehe, T., \& Schildberg-Hörisch, H. (2017). Self-control and crime revisited: Disentangling the effect of self-control on risk taking and antisocial behavior. International Review of Law and Economics, 49, 23-32. doi:10.1016/j.irle.2016.11.001

Gentry, J. A. (2015). Has the ODNI improved U.S. intelligence analysis? International Journal of Intelligence and Counterintelligence, 28(4), 637-661. doi:10.1080/08850607.2015.1050937

Goodman, M. S., \& Omand, D. (2008). What analysts need to understand: The King's intelligence studies program. Studies in Intelligence, 52(4), 1-12 (Extracts, December 2008).

Gurcay-Morris, B. (2016). The use of alternative reasons in probabilistic judgment [Doctoral dissertation, University of Pennsylvania]. UPenn Repository. https://repository.upenn.edu/edissertations/2321/

Haran, U., Ritov, I., \& Mellers, B. A. (2013). The role of actively open-minded thinking in information acquisition, accuracy, and calibration. Judgment and Decision Making, 8(3), 188-201.

Heuer, R. J. (1999). The psychology of intelligence analysis. Washington, DC: CQ Press.

Hogan, J., \& Ones, D. S. (1997). Conscientiousness and integrity at work. In R. Hogan, J. A. Johnson, \& S. R. Briggs (Eds.), Handbook of personality psychology (pp.849-870). San Diego, CA: Academic Press. doi:10.1016/B978-012134645-4/50033-0 
Hong, Y., Liao, H., Hu, J., \& Jiang, K. (2013). Missing link in the service profit chain: A metaanalytic review of the antecedents, consequences, and moderators of service climate. Journal of Applied Psychology, 98(2), 237-267. doi:10.1037/a0031666

Intelligence Reform and Terrorism Prevention Act of 2004 (IRTPA). Pub. L. No. 108-458, 118 Stat. 3688 (Dec. 17, 2004).

Jaramillo, F., Mulki, J. P., \& Marshall, G. W. (2005). A meta-analysis of the relationship between organizational commitment and salesperson job performance: 25 years of research. Journal of Business Research, 58(6), 705-714. doi:10.1016/j.jbusres.2003.10.004

John, O. P., \& Srivastava, S. (1999). The big-five trait taxonomy: History, measurement, and theoretical perspectives. In L. A. Pervin \& O. P. John (Eds.), Handbook of personality: Theory and research (pp.102-138). New York, NY: Guilford Press.

Judge, T. A., Heller, D., \& Mount, M. K. (2002). Five-factor model of personality and job satisfaction: A meta-analysis. Journal of Applied Psychology, 87(3), 530-541. doi:10.1037/0021-9010.87.3.530

Juvina, I., Larue, O., Widmer, C., Ganapathy, S., Nadella, S., Minnery, B., Ramshaw, L., Servan-Schreiber, E., Balick, M., \& Weischedel, R. (2020). Computer-supported collaborative information search for geopolitical forecasting. In W. T. Fu \& H. van Oostendorp (Eds.), Understanding and improving information search: A cognitive approach (1st ed.) (pp.245-266). Cham, Switzerland: Springer International Publishing. doi:10.1007/978-3-030-38825-6

Karvetski, C. W., \& Mandel, D. R. (2020). Coherence of probability judgments from uncertain evidence: Does ACH help? Judgment and Decision Making, 15(6), 939-958.

Karvetski, C. W., Mandel, D. R., \& Irwin, D. (2020). Improving probability judgment in intelligence analysis: From structured analysis to statistical aggregation. Risk Analysis, 40(5), 1040-1057. doi:10.1111/risa.13443

Karvetski, C. W., Olson, K. C., Mandel, D. R., \& Twardy, C. R. (2013). Probabilistic coherence weighting for optimizing expert forecasts. Decision Analysis, 10(4), 305-326. doi:10.1287/deca.2013.0279

Kirchner, J. E., Parker, L. E., Bonner, L. M., Fickel, J. J., Yano, E. M., \& Ritchie, M. J. (2012). 
Roles of managers, frontline staff and local champions, in implementing quality improvement: Stakeholders' perspectives. Journal of Evaluation in Clinical Practice, 18(1), 63-69. doi:10.1111/j.1365-2753.2010.01518.x

Kristof, A. L. (1996). Person-organization fit: An integrative review of its conceptualizations, measurement, and implications. Personnel Psychology, 49(1), 1-49. doi:10.1111/j.17446570.1996.tb01790.x

Locke, E. A. (1976). The nature and causes of job satisfaction. In M.D. Dunnette (Ed.), Handbook of industrial and organizational psychology, Vol. 1 (pp.1297-1343). Chicago, IL: Rand McNally College Publishing Company.

Mandel, D. R., \& Tetlock, P. E. (2018). Correcting judgment correctives in national security intelligence. Frontiers in Psychology, 9, 2640. doi:10.3389/fpsyg.2018.02640

Mandel, D. R., Karvetski, C., \& Dhami, M. K. (2018). Boosting intelligence analysts' judgment accuracy: What works, what fails? Judgment and Decision Making, 13(6), 607-621.

Marchio, J. (2014). Analytic tradecraft and the intelligence community: Enduring value, intermittent emphasis. Intelligence and National Security, 29(2), 159-183. doi:10.1080/02684527.2012.746415

Marcoci, A., Burgman, M., Kruger, A., Silver, E., McBride, M., Singleton Thorn, F., Fraser, H., Wintle, B. C., Fidler, F., \& Vercammen, A. (2019). Better together: Reliable application of the post-9/11 and post-Iraq US intelligence tradecraft standards requires collective analysis. Frontiers in Psychology, 9:2634. doi:10.3389/fpsyg.2018.02634

Marcus, B., \& Schuler, H. (2004). Antecedents of counterproductive behavior at work: A general perspective. Journal of Applied Psychology, 89(4), 647-660. doi:10.1037/00219010.89.4.647

McCormac, A., Zwaans, T., Parsons, K., Calic, D., Butavicius, M., \& Pattinson, M. (2017). Individual differences and information security awareness. Computers in Human Behavior, 69,151-156. doi:10.1016/j.chb.2016.11.065

McCrae, R. R., \& John, O. P. (1992). An introduction to the five-factor model and its applications. Journal of Personality, 60(2), 175-215. doi:10.1111/j.14676494.1992.tb00970.x 
McCrae, R. R., Costa, P. T., Del Pilar, G. H., Rolland, J., \& Parker, W. D. (1998). Cross-cultural assessment of the five-factor model: The revised NEO personality inventory. Journal of Cross-Cultural Psychology, 29(1), 171-188. doi:10.1177/0022022198291009

Mellers, B., Stone, E., Murray, T., Minster, A., Rohrbaugh, N., Bishop, M., Chen, E., Baker, J., Hou, Y., Horowitz, M., Ungar, L., \& Tetlock, P. (2015). Identifying and cultivating superforecasters as a method of improving probabilistic predictions. Perspectives on Psychological Science, 10(3), 267-281. doi:10.1177/1745691615577794

Mellers, B., Stone, E., Atanasov, P., Rohrbaugh, N., Metz, S. E., Ungar, L., Bishop, M. M., Horowitz, M., Merkle, E., \& Tetlock, P. (2015). The psychology of intelligence analysis: Drivers of prediction accuracy in world politics. Journal of Experimental Psychology: Applied, 21(1), 1-14. doi:10.1037/xap0000040

Meyer, J. P., Stanley, D. J., Herscovitch, L., \& Topolnytsky, L. (2002). Affective, continuance, and normative commitment to the organization: A meta-analysis of antecedents, correlates, and consequences. Journal of Vocational Behavior, 61(1), 20-52. doi:10.1006/jvbe.2001.1842

Office of Personnel Management (2015). 2015 United States federal employee survey. Retrieved from https://www.opm.gov/fevs/public-data-file/.

Office of the Director of National Intelligence (2021). Independent IC Analytic Ombudsman's on Politicization of Intelligence. Retrieved from https://fas.org/irp/eprint/politicization.pdf.

Office of the Director of National Intelligence (2007). Intelligence community directive number 203: Analytic standards. Retrieved from https://www.dni.gov/files/documents/ICD/ICD \%20203\%20 Analytic\%20Standards\%20pdf-unclassified.pdf.

Office of the Director of National Intelligence (2015). Intelligence community directive number 203: Analytic standards. Retrieved from https://www.dni.gov/files/documents/ICD/ICD \%20203\%20 Analytic\%20Standards.pdf.

Ortiz, F. A., Church, A. T., Vargas-Flores, J. D. J., Ibáñez-Reyes, J., Flores-Galaz, M., IuitBriceño, J. I., \& Escamilla, J. M. (2007). Are indigenous personality dimensions culturespecific? Mexican inventories and the five-factor model. Journal of Research in Personality, 41(3), 618-649. doi:10.1016/j.jrp.2006.07.002 
Organ, D. W., \& Lingl, A. (1995). Personality, satisfaction, and organizational citizenship behavior. The Journal of Social Psychology, 135(3), 339-350. doi:10.1080/00224545.1995.9713963

Ostroff, C., Shin, Y., \& Kinicki, A. J. (2005). Multiple perspectives of congruence: Relationships between value congruence and employee attitudes. Journal of Organizational Behavior, 26(6), 591-623. doi:10.1002/job.333

Ozer, D. J., \& Benet-Martínez, V. (2006). Personality and the prediction of consequential outcomes. Annual Review of Psychology, 57(1), 401-421. doi:10.1146/annurev.psych.57.102904.190127

Pigg, V. H. (2009). Common analytic standards: Intelligence community directive \#203 and US Marine Corps intelligence. Small Wars Journal. Retrieved from http://smallwarsjournal.com/blog/ journal/docs-temp/260-pigg.pdf.

Sheley, J. F., \& Nock, S. L. (1979). Determinants of police job satisfaction. Sociological Inquiry, 49(1), 49-55. doi:10.1111/j.1475-682X.1979.tb00359.x

Slaughter, J. E., Cooper, D. A., \& Gilliland, S. W. (2020). Good apples in good barrels: Conscientious people are more responsive to code enforcement. Journal of Occupational and Organizational Psychology, doi:10.1111/joop.12325

Smith, S. M., \& Levin, I. P. (1996). Need for cognition and choice framing effects. Journal of Behavioral Decision Making, 9(4), 283-290. doi:10.1002/(SICI)10990771(199612)9:4<283::AID-BDM241>3.0.CO;2-7

Stanley, D. J., Meyer, J. P., \& Topolnytsky, L. (2005). Employee cynicism and resistance to organizational change. Journal of Business and Psychology, 19(4), 429-459. doi:10.1007/s10869-005-4518-2

Stanovich, K. E., \& Toplak, M. E. (2019). The need for intellectual diversity in psychological science: Our own studies of actively open-minded thinking as a case study. Cognition, 187,156-166. doi:10.1016/j.cognition.2019.03.006

Taylor, S. E. (1991). Asymmetrical effects of positive and negative events: The mobilizationminimization hypothesis. Psychological Bulletin, 110(1), 67-85. doi:10.1037//00332909.110.1.67 
Tetlock, P. E. (2005). Expert political judgment: How good is it? How can we know? Princeton, NJ: Princeton University Press.

Tetlock, P. E., \& Gardner, D. (2015). Superforecasting: The art and science of prediction. New York, NY: Crown Publishers/Random House.

Toplak, M. E., West, R. F., \& Stanovich, K. E. (2017). Real-World correlates of performance on heuristics and biases tasks in a community sample. Journal of Behavioral Decision Making, 30(2), 541-554. doi:10.1002/bdm.1973

Travers, M. (2007). The new bureaucracy: Quality assurance and its critics. Bristol, UK: Policy Press.

Verquer, M. L., Beehr, T. A., \& Wagner, S. H. (2003). A meta-analysis of relations between person-organization fit and work attitudes. Journal of Vocational Behavior, 63(3), 473489. doi:10.1016/s0001-8791(02)00036-2

Weiner, B. J. (2009). A theory of organizational readiness for change. Implementation Science, 4(1), 67-67. doi:10.1186/1748-5908-4-67

West, R. F., Toplak, M. E., \& Stanovich, K. E. (2008). Heuristics and biases as measures of critical thinking: Associations with cognitive ability and thinking dispositions. Journal of Educational Psychology, 100(4), 930-941. doi:10.1037/a0012842

Whitesmith, M. (2019). The efficacy of ACH in mitigating serial position effects and confirmation bias in an intelligence analysis scenario. Intelligence and National Security, 34(2), 225-242. doi:10.1080/02684527.2018.1534640

Yoon, S., Choi, D., \& Park, J. (2007). Service orientation: Its impact on business performance in the medical service industry. The Service Industries Journal, 27(4), 371-388. doi:10.1080/02642060701346375

Zelik, D., Patterson, E. S., \& Woods, D. D. (2007a). Understanding rigor in information analysis. In K. Mosier \& U. Fischer (Eds.), Proceedings of the eighth international NDM conference (pp.1-8). Pacific Grove, CA.

Zelik, D., Patterson, E. S., \& Woods, D. D. (2007b). Judging sufficiency: How professional intelligence analysts assess analytical rigor. Proceedings of the Human Factors and Ergonomics Society Annual Meeting, 51(4), 318-322. doi:10.1177/154193120705100436 
Table 1. Component Loadings of ICD203-PAS. Item number shows its order in the scale.

\begin{tabular}{|c|c|c|c|c|}
\hline \multirow{3}{*}{$x^{2}$} & \multirow{3}{*}{ Item } & \multicolumn{3}{|c|}{ Component } \\
\hline & & \multirow{2}{*}{$\begin{array}{c}1 \\
\text { Unbiased }\end{array}$} & \multirow{2}{*}{$\begin{array}{c}2 \\
\text { Rigorous }\end{array}$} & \multirow{2}{*}{$\begin{array}{c}3 \\
\text { Relevant }\end{array}$} \\
\hline & & & & \\
\hline 1 & Unbiased, objective perspective & .842 & .172 & .135 \\
\hline 2 & Not distorted/altered to support a view & .792 & .043 & .139 \\
\hline 12 & Makes the most accurate judgments possible & .778 & .179 & .285 \\
\hline 6 & Express uncertainties or confidence in judgments & .594 & .208 & .458 \\
\hline 5 & Describe source quality and credibility & .192 & .844 & .001 \\
\hline 8 & Incorporate alternative analysis where appropriate & .103 & .749 & .215 \\
\hline 13 & Incorporates visual information where appropriate & -.105 & .637 & .272 \\
\hline 7 & Distinguish intelligence vs analysts' assumptions & .422 & .609 & .085 \\
\hline 10 & Present in ways to facilitate clear understanding & .275 & .481 & .411 \\
\hline 9 & Demonstrate relevance to Canadian national security & .057 & .307 & .708 \\
\hline 11 & Delivers consistent key message or highlights changes & .129 & .148 & .642 \\
\hline 3 & Delivered in a timely manner & .395 & .150 & .639 \\
\hline 4 & Informed by all relevant information & .434 & -.030 & .572 \\
\hline
\end{tabular}


Table 2. Descriptive statistics for ICD203-PAS, ICD203-OCS, and the difference between these measures (ICD203-PAS - ICD203-OCS).

\begin{tabular}{|c|c|c|c|c|c|c|}
\hline \multirow{2}{*}{ Item } & \multicolumn{2}{|c|}{ ICD203-PAS } & \multicolumn{2}{|c|}{ ICD203-OCS } & \multicolumn{2}{|c|}{ Difference } \\
\hline & Mean & $S D$ & Mean & $S D$ & Mean & $S D$ \\
\hline 1 & 6.71 & 0.67 & 5.79 & 1.07 & 0.93 & 1.07 \\
\hline 2 & 6.71 & 0.68 & 6.10 & 0.99 & 0.61 & 0.94 \\
\hline 3 & 6.71 & 0.57 & 5.49 & 1.37 & 1.22 & 1.38 \\
\hline 4 & 6.62 & 0.62 & 5.76 & 1.14 & 0.86 & 1.16 \\
\hline 5 & 6.07 & 1.14 & 4.84 & 1.69 & 1.22 & 1.72 \\
\hline 6 & 6.55 & 0.63 & 5.67 & 1.22 & 0.88 & 1.19 \\
\hline 7 & 6.47 & 0.73 & 5.51 & 1.29 & 0.96 & 1.25 \\
\hline 8 & 5.74 & 1.24 & 4.44 & 1.68 & 1.31 & 1.81 \\
\hline 9 & 6.31 & 0.97 & 5.63 & 1.42 & 0.69 & 1.56 \\
\hline 10 & 6.64 & 0.72 & 5.79 & 1.18 & 0.85 & 1.12 \\
\hline 11 & 6.44 & 0.84 & 5.74 & 1.22 & 0.70 & 1.31 \\
\hline 12 & 6.82 & 0.47 & 6.00 & 1.07 & 0.82 & 1.08 \\
\hline 13 & 5.99 & 1.01 & 5.82 & 1.28 & 0.18 & 1.45 \\
\hline Overall & 6.45 & 0.49 & 5.58 & 0.84 & 0.86 & 0.78 \\
\hline
\end{tabular}




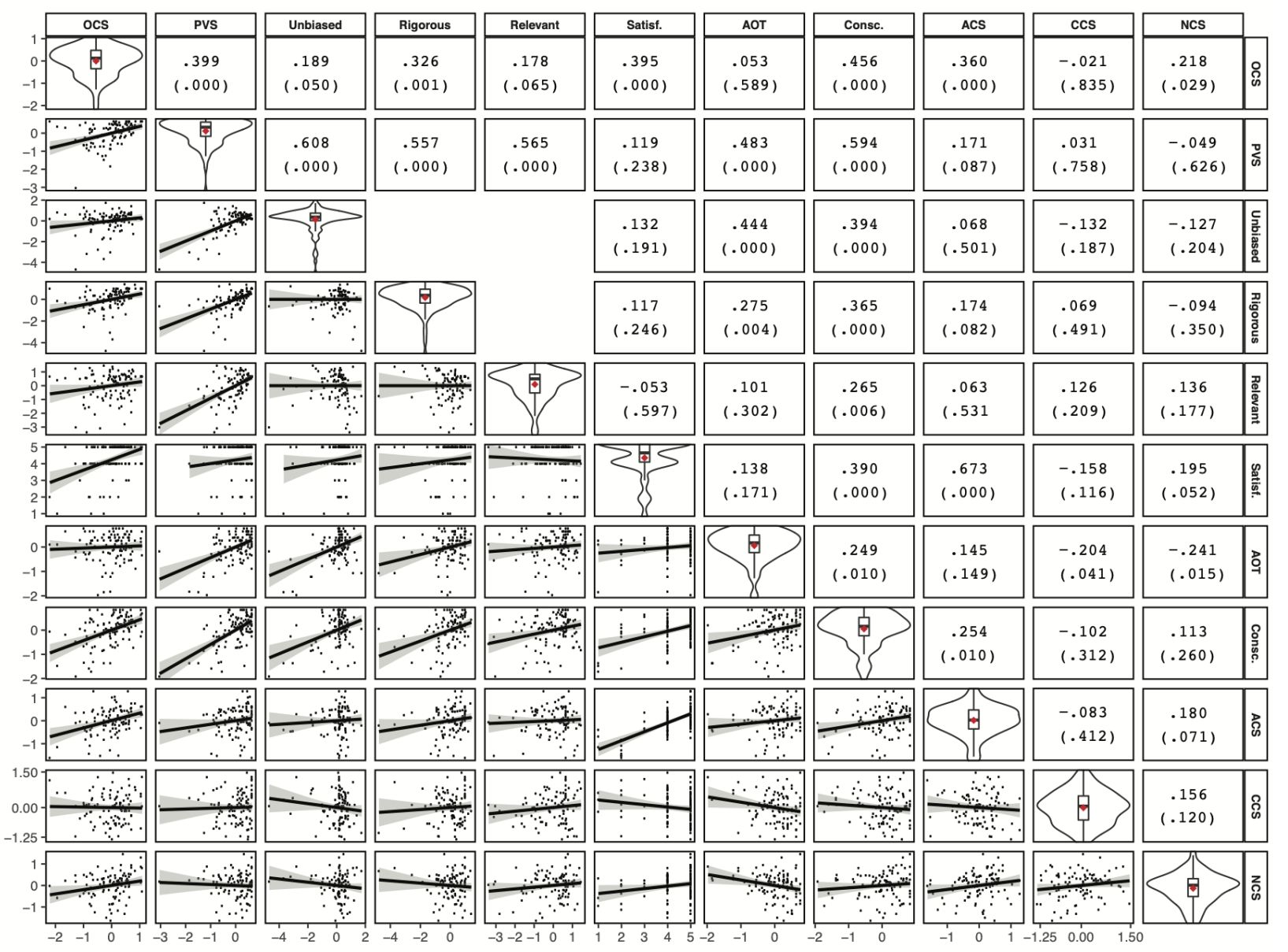

Figure 1. Bivariate analyses of the ICD203 scales. Cells above the diagonal show $r$ and $p$ values.

The diagonal shows scale distributions and means. Cells below the diagonal show bivariate scatter plots. OCS = organizational compliance scale; PAS = professional attitudes scale; Satisf. $=$ job satisfaction; $\mathrm{AOT}=$ actively open-minded thinking; Consc. $=$ conscientiousness; $\mathrm{ACS}=$ affective commitment scale; $\mathrm{CCS}$ = continuance commitment scale; NCS = normative commitment scale. 